\title{
Single spot albumin to creatinine ratio: A simple marker of long-term prognosis in non-ST segment elevation acute coronary syndromes
}

\author{
Claudio Cesar Higa, Fedor Anton Novo, Ignacio Nogues, Maria Graciana Ciambrone, \\ Maria Sol Donato, Maria Jimena Gambarte, Natalia Rizzo, \\ Maria Paula Catalano, Eugenio Korolov, Pablo Dino Comignani \\ Coronary Care Unit, Department of Internal Medicine, Hospital Alemán, Buenos Aires, Argentina
}

\begin{abstract}
Background: Microalbuminuria is a known risk factor for cardiovascular morbidity and mortality suggesting that it should be a marker of endothelial dysfunction. Albumin to creatinine ratio (ACR) is an available and rapid test for microalbuminuria determination, with a high correlation with the 24-h urine collection method. There is no prospective study that evaluates the prognostic value of ACR in patients with non ST-segment elevation acute coronary syndromes (NSTE-ACS). The purpose of our study was to detect the long-term prognostic value of ACR in patients with NSTE-ACS.

Methods: Albumin to creatinine ratio was estimated in 700 patients with NSTE-ACS at admission. Median follow-up time was 18 months. The best cutoff point of ACR for death or acute myocardial infarction was $20 \mathrm{mg} / \mathrm{g}$. Twenty-two percent of patients had elevated ACR.

Results: By multivariable Cox regression analysis, ACR was an independent predictor of the clinical endpoint: odds ratio 5.8 (95\% confidence interval [CI] 2-16), log-rank $2 p<0.0001$ in a model including age > 65 years, female gender, diabetes mellitus, creatinine clearance, glucose levels at admission, elevated cardiac markers (troponin T/CK-MB) and ST segment depression. The addition of ACR significantly improved GRACE score C-statistics from 0.69 (95\% CI 0.59-0.83) to 0.77 (95\% CI 0.65-0.88), SE 0.04, $2 p=0.03$, with a good calibration with both models.

Conclusions: Albumin to creatinine ratio is an independent and accessible predictor of long-term adverse outcomes in NSTE-ACS, providing additional value for risk stratification. (Cardiol J 2016; 23, 3: 236-241)
\end{abstract}

Key words: microalbuminuria, acute coronary syndromes, prognosis

\section{Introduction}

Cardiovascular disease is currently the main cause of death in the Western world. In 2008, according to the World Health Organization (WHO), $7,500,000$ people died of ischemic heart disease, representing $12.8 \%$ of total deaths worldwide [1].
Non-ST-segment elevation acute coronary syndrome (NSTE-ACS) represents a prevalent and heterogeneous population with a broad spectrum of outcomes [2].

Microalbuminuria (MA), defined as urinary albumin excretion elevation between 30 and $300 \mathrm{mg}$ /day was initially used as a kidney damage marker

Address for correspondence: Dr Claudio C. Higa, MD, Av. Pueyredon 1640, Buenos Aires City, Argentina, ZP 1118, tel/fax: (54) 114 8277000, e-mail: chiga@hospitalaleman.com 
in diabetic patients [3-5] but subsequently it was shown to be a good marker of risk of total and cardiovascular mortality among diabetic and hypertensive patients, as well as in the overall population [6-8]. MA also proved to be a marker of short- and long-term follow-up adverse events in patients with acute myocardial infarction (AMI) [9-14]. Finally, there is a broad evidence about the close correlation between the albumin to creatinine ratio (ACR) obtained from a spot urine sample with the MA collected in a $24 \mathrm{~h}$ period [15].

There is no information on the prognostic value of ACR in a NSTE-ACS population.

\section{Methods}

This study was conducted to test prospectively the hypothesis that ACR is independently associated with long-term adverse outcomes in NSTE-ACS patients. We excluded those with history of renal failure defined as a glomerular filtration rate below $60 \mathrm{~mL} / \mathrm{min} / 1.73 \mathrm{~m}^{2}$ by the use of Modification of Diet in Renal Disease equation, history of macroalbuminuria, or previous diuretic treatment $\geq 24 \mathrm{~h}$ before admission, urinary and respiratory tract infections. The primary endpoint analyzed was the occurrence of death and/or AMI at 24-month follow-up. AMI is defined by WHO criteria (ischemic symptoms, changes in ST segment, development of new $Q$ waves, typical creatinine phosphokinase curve $\times 3$ post angioplasty, and $\times 5$ post coronary artery bypass graft surgery [CABG]). All patients gave their written informed consent before their inclusion in the study. The protocol was approved by our local Review Board Committee.

GRACE score 2.0 was calculated for all the patients of the study [2].

Follow-up assessments were performed by means of questionnaires, examinations, telephone interviews, review of medical records, and reports from personal physicians.

The study was approved by our institutional Review Board and conducted in compliance with the Declaration of Helsinki, Good Clinical Practice guidelines, and local regulatory requirements.

\section{Biochemical considerations}

A urine sample was taken during the first $24 \mathrm{~h}$ following admission (preferably in the morning hours). The samples were centrifuged at 3,000 rpm, storing them at $-20^{\circ} \mathrm{C}$ for later analysis. The principle of the ACR measurement test is immunoturbidimetry. This method is based on the reaction of human albumin antibodies with the antigen. The complexes are then measured after its agglutination. The COBAS 6000 analyzer (ROCHE) was used for sample processing. The analytical detection limits of the assay were $3 \mathrm{mg} / \mathrm{g}$ and $400 \mathrm{mg} / \mathrm{g}$. The test variation coefficient was $3.8 \%$.

\section{Statistical aspects}

Analysis of distribution of continuous variables was performed using the Kolmogorov-Smirnov test and analysis of kurtosis-skewness. Data were expressed as mean and standard deviation, or as its median and its $25^{\text {th }}$ and $75^{\text {th }}$ interquartile and a comparison was made using the Student's t-test or the Mann-Whitney-Wilcoxon test for independent groups, according to its parametric or nonparametric distribution, respectively.

Discrete variables were expressed as percentages. We used the $\chi^{2}$ test for comparison purposes. The cross product ratio will be expressed as odds ratio (OR) with a confidence interval of $95 \%(95 \% \mathrm{CI})$. $\mathrm{C}$-statistics was used to detect the best cutoff value of the ACR in relation to the primary endpoint and to compare discrimination capacity between the GRACE score alone and with the addition of the ACR.

Actuarial survival curves were constructed by the Kaplan-Meier method based on the study endpoint for each dichotomous variable. The log-rank test was used for comparisons. Cox proportional regression models were used to identify variables that were independently associated with the endpoint. Variables with a value of $p<0.1$ in the bivariate analysis, those (mostly historical) which had caused confusion in the relationship between the ACR and the endpoint being were included in the model. Model calibration was assessed through the Hosmer-Lemeshow test. For the correlation between continuous variables the Pearson $P$ coefficient was used. All statistical comparisons were 2 -tailed, considering significant a probability (2 p) of less than $5 \%$. For statistical analysis the IBM Statistics SPSS version 19 software and the MedCalc software version 11.6.1. (Mariakerke, Belgium) were used for construction and comparison of C-statistics. To test the additional predictive value of $\mathrm{ACR}$ we compared $\mathrm{C}$-statistics for GRACE score alone and the GRACE score plus the ACR information.

\section{Results}

Seven hundred consecutive patients were analyzed with a final diagnosis of NSTE-ACS. Twenty-six patients were excluded due to history 
Table 1. Baseline demographics and clinical characteristics.

\begin{tabular}{|c|c|c|c|c|}
\hline Variable & $\begin{array}{c}\text { Total } \\
(\mathrm{n}=700)\end{array}$ & $\begin{array}{c}\mathrm{ACR} \leq 20 \mathrm{mg} / \mathrm{g} \\
(\mathrm{n}=574)\end{array}$ & $\begin{array}{c}A C R>20 \mathrm{mg} / \mathrm{g} \\
(\mathrm{n}=126)\end{array}$ & $\mathbf{P}$ \\
\hline Age [years] & $63(56-73)$ & $61(5-71)$ & $68(57-76)$ & 0.01 \\
\hline Women & $245(35 \%)$ & $212(37 \%)$ & $34(27 \%)$ & 0.08 \\
\hline Diabetes & $133(19 \%)$ & $92(16 \%)$ & $35(28 \%)$ & 0.01 \\
\hline Hypertension & $455(65 \%)$ & $356(62 \%)$ & $94(75 \%)$ & 0.03 \\
\hline Dyslipidemia & $385(55 \%)$ & $310(54 \%)$ & $72(57 \%)$ & 0.6 \\
\hline Active smoking & $301(43 \%)$ & $241(42 \%)$ & $57(45 \%)$ & 0.5 \\
\hline Previous AMI: & $133(19 \%)$ & $126(22 \%)$ & $23(18 \%)$ & 0.9 \\
\hline CABG & $37(5.3 \%)$ & $32(5.6 \%)$ & $9(7.1 \%)$ & 0.9 \\
\hline $\mathrm{PCl}$ & $99(14.2 \%)$ & $86(15 \%)$ & $13(10 \%)$ & 0.09 \\
\hline Angina & $46(6.6 \%)$ & $37(6.5 \%)$ & $15(11.8 \%)$ & 0.9 \\
\hline Stroke & $21(3 \%)$ & $14(2.5 \%)$ & $9(7.1 \%)$ & 0.04 \\
\hline COPD & $22(3.2 \%)$ & $18(3.1 \%)$ & $7(5.9 \%)$ & 0.1 \\
\hline ACE-I/ARB & $287(41 \%)$ & $224(39 \%)$ & $62(49 \%)$ & 0.07 \\
\hline Beta-blockers & $245(35 \%)$ & $212(37 \%)$ & $53(42 \%)$ & 0.4 \\
\hline Aspirin & $245(35 \%)$ & $103(18 \%)$ & $31(25 \%)$ & 0.2 \\
\hline ST depression at admission & $98(14 \%)$ & $86(15 \%)$ & $25(20 \%)$ & 0.2 \\
\hline Severe LV dysfunction & $10(1.5 \%)$ & $7(1.3 \%)$ & $3(2.4 \%)$ & 0.6 \\
\hline Cardiogenic shock & $28(4 \%)$ & $11(2 \%)$ & $13(10 \%)$ & 0.001 \\
\hline Peak troponin $\mathrm{T}[\mathrm{ng} / \mathrm{dL}]$ : & $0.01(0-0.21)$ & $0.001(0-0.15)$ & $0.1(0-0.9)$ & 0.0001 \\
\hline CK $[\mathrm{UI} / \mathrm{L}]$ & $121(73-258)$ & $115(70-211)$ & $188(88-560)$ & 0.02 \\
\hline CK-MB [UI/L] & $16(12-34)$ & $15(11-28)$ & $18(13-69)$ & 0.006 \\
\hline Serum creatinine $[\mathrm{mg} / \mathrm{dL}]$ & $0.8(0.9-1.1)$ & $0.9(0.8-1)$ & $1(0.8-1.2)$ & 0.0001 \\
\hline Creatinine clearance [mL/h] & $66(86-107)$ & $90(70-110)$ & $70(50-90)$ & 0.001 \\
\hline Admission glycaemia [mg/dL] & $110(98-133)$ & 108 (97-123) & $121(101-166)$ & 0.0001 \\
\hline Systolic blood pressure [mm Hg] & $140(120-150)$ & $140(120-150)$ & $140(120-160)$ & 0.1 \\
\hline Heart rate $[\mathrm{bpm}]$ & $70(63-80)$ & $72(64-80)$ & $75(63-85)$ & 0.2 \\
\hline
\end{tabular}

ACE-I/ARB - angiotensin converting enzyme inhibitors/angiotensin II receptor blockers; AMI - acute myocardial infarction; ACR — albumin to creatine ratio; CABG - coronary artery bypass graft; $\mathrm{CK}$ - creatinine phosphokinase; CK-MB - creatinine kinase MB; COPD - chronic obstructive pulmonary disease; LV — left ventricular; $\mathrm{PCl}$ - percutaneous coronary intervention

of renal failure and next 27 for prior treatment with loop-diuretics.

The average age was $63 \pm 12$ years old. Thirty percent were women, $65 \%$ had hypertension, and one fifth were diabetic. Half of the studied population had a history of dyslipidemia and $43 \%$ were active smokers, $19 \%$ had a history of ACS, $5.3 \%$ had undergone $\mathrm{CABG}$ and $14.2 \%$ coronary angioplasty. Table 1 describes the demographic and clinical baseline characteristics of the population.

The medium ACR was $6 \mathrm{mg} / \mathrm{g}$ (interquartile range 25-75: $0-20 \mathrm{mg} / \mathrm{g}$ ). For the lineal logistic regression, both the diabetes and previous stroke/ /transient ischemic attack were the only variables independently associated with ACR as continuous variables: $p=0.02$ and $p=0.004$, respectively.
Thirty percent of the studied population had no history of diabetes or hypertension.

Patients with elevated ACR were significantly associated with history of hypertension and diabetes, and with peak concentrations of troponin $\mathrm{T}$, total creatinine phosphokinase, creatinine kinase (CK)-MB, plasma creatinine and plasma glucose.

On the other hand, ACR had a negative correlation with creatinine clearance values.

Median follow-up time was 18 (12-24) months. Ninety-five percent of the appointments were personal contacts as hospital controls or in a private office.

Based on the C-statistics analysis, the best ACR cutoff value associated with the clinical endpoint (death/AMI) was $20 \mathrm{mg} / \mathrm{g}$. Twenty-two 


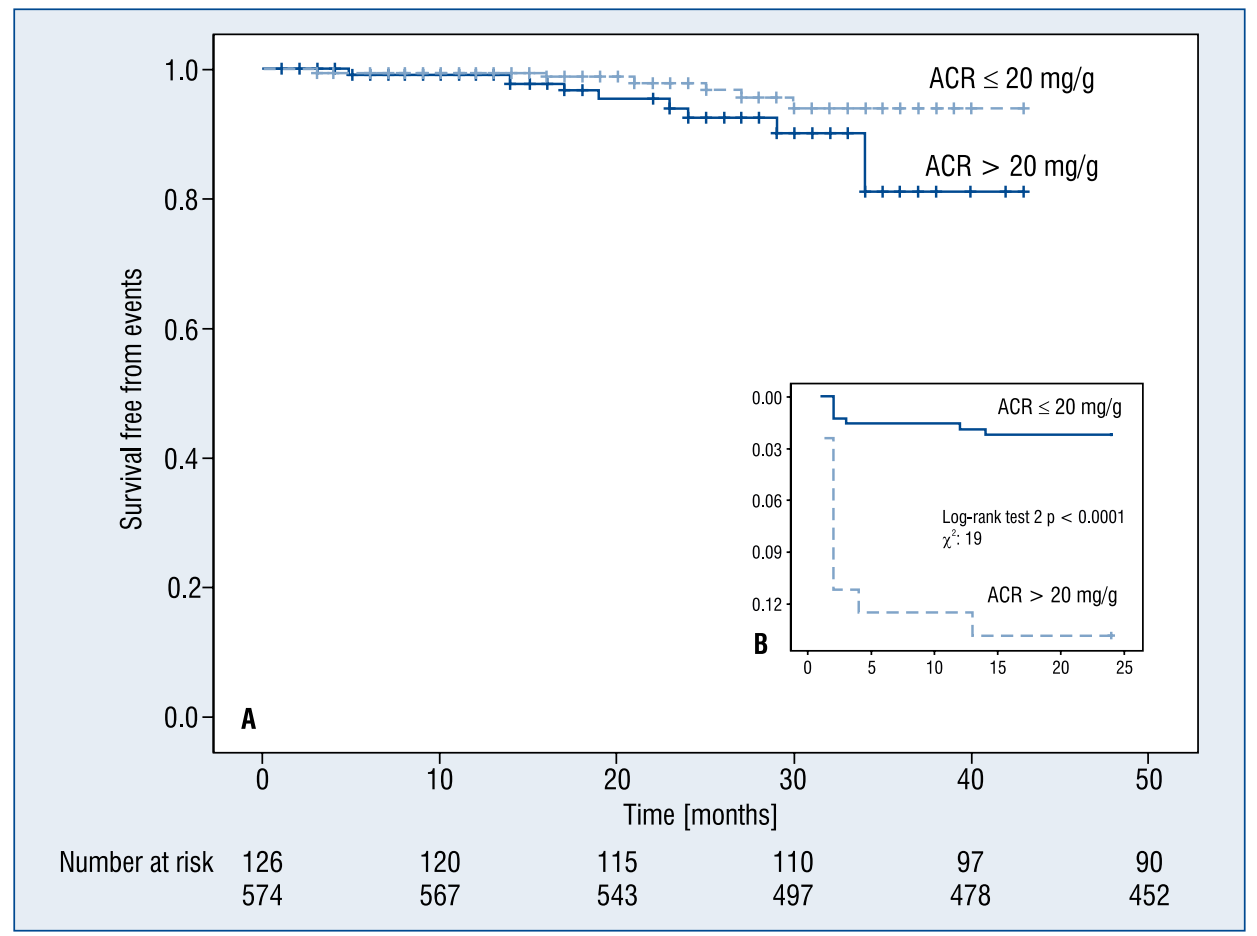

Figure 1. A. Event-free actuarial survival curves at 6-month follow-up in patients with an albumin to creatinine ratio $(A C R) \leq 20 \mathrm{mg} / \mathrm{g}$ vs. those with $A C R>20 \mathrm{mg} / \mathrm{g}$; B. Event-free survival curves plotted on a logarithmic scale.

percent of the population presented higher values than this cutoff value and $1.2 \%$ corresponded to values that were compatible with macroalbuminuria $(\mathrm{ACR}>300 \mathrm{mg} / \mathrm{g})$.

At follow-up, the endpoint incidence was significantly higher among those with an ACR $>20 \mathrm{mg} / \mathrm{g}$ : $12 \%$ vs. $2.2 \%, 2 \mathrm{p}=0.0001$. This association was detected both in patients with history of hypertension (OR 6.8, 95\% CI 1.2-37, p = 0.002) and in those without history of hypertension (OR 1.3, 95\% CI 1.1-5.4, $\mathrm{p}=0.02$ ), in diabetics (OR 2.3, $95 \% \mathrm{CI} 1.7-7.1, \mathrm{p}=0.01)$ and in non-diabetics (OR 1.5, 95\% CI 1.1-7.1, $\mathrm{p}=0.01$ ), and patients with unstable angina (OR 6.8, 95\% CI 1.2-37, $\mathrm{p}=0.02)$ and in those with myocardial infarction (OR 1.3, 95\% CI 1.2-5.4, $\mathrm{p}=0.04$ ).

Albumin to creatininee ratio values were higher in patients with events at the follow-up than in those with no events: $20 \mathrm{mg} / \mathrm{g}(0-42) \mathrm{vs} .5 \mathrm{mg} / \mathrm{g}$ (0-15), $2 \mathrm{p}<0.001$.

Combined endpoint was achieved in $31(4.5 \%)$ cases of the total population. There were $20(3.3 \%)$ deaths: (17/20) 85\% were cardiac deaths, 11 of 17 (64\%) due to cardiogenic shock/acute pulmonary edema. Endpoints were higher in those with ACR $>20 \mathrm{mg} / \mathrm{g}$ than those with ACR $\leq 20 \mathrm{mg} / \mathrm{g}: 7 \%$ vs. $2.9 \%, \mathrm{p}=0.04$.
Kaplan-Meier analysis demonstrated that patients with ACR $>20 \mathrm{mg} / \mathrm{g}$ had a higher prevalence of death/AMI at 24 months; log-rank test $\chi^{2} 19$, $2 \mathrm{p}<0.0001$ (Fig. 1).

In the Cox multivariate regression model, ACR was found to be an independent predictor of death/AMI: OR 5.8 (95\% CI 2-16), 2 p < 0.001, adjusted for age $>65$ years, female gender, diabetes mellitus, creatinine clearance, glucose levels at admission, elevated cardiac markers (troponin $\mathrm{T} /$ /CK-MB) and ST segment depression (Table 2).

C-statistics of GRACE score alone was 0.69 (95\% CI 0.59-0.83). This value increased with the addition of the ACR value from 0.69 (95\% CI 0.59-0.83) to 0.77 (95\% CI 0.65-0.88), SE 0.04, $2 \mathrm{p}=0.03$.

Hosmer-Lemeshow test showed a good calibration in both models: its $\mathrm{X}^{2}$ for the GRACE score was $1.6(p=0.3)$ and for the GRACE score with the addition of ACR it was $1.3(\mathrm{p}=0.8)$, respectively, denoting a good concordance between observed and expected events in all subgroups of risk.

\section{Discussion}

To our knowledge, this is the first prospective study that demonstrated the independent predic- 
Table 2. Time dependent Cox regression analysis for long-term follow-up combined endpoint.

\begin{tabular}{lcccc}
\hline Variable & Regression coefficient B & Standard error & Odds ratio (Cl 95\%) & $\mathbf{2 ~ p ~}$ \\
\hline Female gender & 1.01 & 0.78 & $2.7(0.5-12)$ & 0.19 \\
Age $>$ 65 years & 0.64 & 0.60 & $1.9(0.6-6.2)$ & 0.02 \\
Diabetes mellitus & 0.85 & 0.79 & $1.4(0.9-1.9)$ & 0.4 \\
Elevated cardiac markers* & 0.21 & 0.636 & $1.3(0.35-4.3)$ & 0.012 \\
ST segment depression & 1.03 & 0.68 & $2.7(1.7-10)$ & 0.04 \\
Creatinine clearance $[\mathrm{mL} / \mathrm{min}]$ & 0.28 & 0.62 & $1.3(1.1-4.4)$ & 0.06 \\
ACR $>20 \mathrm{mg} / \mathrm{g}$ & 1.02 & 0.02 & $5.8(2-16)$ & 0.0001 \\
\hline
\end{tabular}

*Troponin T/creatinine kinase-MB; ACR - albumin to creatinine ratio; $\mathrm{Cl}$ - confidence interval

tive power of ACR in NSTE-ACS patients. As mentioned above, previous reports assessed the prognostic value of MA in observational studies of patients with diagnosis of AMI. There is just one experience with MA in NSTE-ACS patients but derived from randomized controlled study with a selected population [16].

We chose ACR measurement for its high correlation with the $24 \mathrm{~h}$ urine MA method, simple collection and widespread availability.

As occurred in previous studies, the predictive cutoff value of ACR (>20 mg/g) for cardiovascular endpoints was below the conventional thresholds for the detection of renal injury (e.g. $30 \mathrm{mg} / \mathrm{g}$ ) [17, $18]$, taking into account a continuous relationship of this marker and the outcomes.

It is important to highlight that this association was observed regardless of the renal function state and of the presence or absence of history of diabetes.

We highlight the incremental value of a robust stratification tool like the GRACE score with the addition of ACR measurement, both in patients with unstable angina and NSTE-ACS.

The association mechanism between MA and prognosis among ACS patients is unknown. To date, there has been some evidence regarding its association with the process of atherosclerosis. For example, the MA was related to signs of endothelial dysfunction (e.g. lower vascular reactivity to vasodilators and increased activity of endothelial adhesion molecules). In the same way, MA was associated with increased carotid intima-media thickness in patients with type 1 diabetes. There is also evidence of its association with typical signs of inflammation, such as leukocytosis and an increase of inflammatory markers.

Finally, there are reports about its relationship with increased coagulation factor activity, such as the production of tissue factor and factor VII [19-28].

\section{Therapeutic implications}

In studies such as the ABCD and RENAAL, it has been noted that the reduction of MA in diabetic patients treated with angiotensin converting enzyme inhibitors/angiotensin II receptor blockers was associated with long-term reduction of cardiovascular events. In the future, the impact on the reduction of MA in patients with NSTE-ACS with this pharmacological agent remains an attractive hypothesis of a study [29, 30].

\section{Limitations of the study}

Our study has several limitations. First, it is a single center study, so our findings must be confirmed in a multicenter cohort. Second, ACR was measured only at admission, in order to provide useful information for risk stratification, but we did not collect serial samplings during the hospitalization period. Finally, MA was not measured by the standard $24 \mathrm{~h}$ urine sampling in order to detect correlation with ACR and its association with the clinical events.

\section{Conclusions}

Microalbuminuria determined as ACR, could in the future become an accessible and simple tool for risk stratification in NSTE-ACS, underlining that the ACR may be considered for risk stratification in clinical practice. This observation should be validated in other external populations.

Conflicts of interest: None declared

\section{References}

1. World Health Organization. The Top Causes of death. Available at: http://www.who.int/mediacentre/factsheets/fs310/en/. Updated May 2014.

2. Granger CB, Goldberg RJ, Dabbous O et al.; for the Global Registry of Acute Coronary Events Investigators. Predictors of 
hospital morbidity in the global registry of acute coronary events. Arch Intern Med, 2003; 163: 2345-2353.

3. Bradows RG, Nichols D, Shaker G, Kubasik NP. Evaluation of a new radioimmunoassay for urinary albumin. Diabetes Care, 1986; 9: 189-193.

4. Viberti GC, Hill RD, Jarret RT, Argyropoulos A, Mahmud U, Keen H. MA is a predictor of clinical nephropathy in type 1 diabetes. Lancet, 1982; 1: 1430-1432.

5. Mogensen CE, Christensen CK. Predicting diabetic nephropathy in insulin-dependent patients. N Engl J Med, 1984; 31: 89-93.

6. Valmadrid CT, Klein R, Moss SE, Klein BE. The risk of cardiovascular disease morbidity associated with microalbuminuria and gross proteinuria in persons with older-onset diabetes mellitus. Arch Intern Med, 2000; 160: 1093-1100.

7. Dogra G, Rich L, Stanton K, Watts Parving H. Microalbuminuria in essential hypertension and diabetes. J Hypertens, 1996; 14: S89-S94.

8. Horner P. Fliser D, Klimm HP, Ritz E. Albuminuria in normotensive and hypertensive attending offices of general practitioners. J Hypertens, 1995; 14: 655-660.

9. Gosling P, Hughes EA, Reynolds JP, Fox JP. Microalbuminuria is an early response following acute myocardial infarction. Eur Heart J, 1991; 12: 508-513.

10. Taskiran M, Feldt-Rasmussen B, Jensen GB, Jensen JS. Urinary albumin excretion in hospitalized patients with acute myocardial infarction. Prevalence of microalbuminuria and correlation to left ventricle wall thickness. Scand Cardiovasc J, 1998; 32: 163-166.

11. Berton G, Citro T, Palmieri R, Petucco S, De Toni R, Palatini P. Albumin excretion rate increases during acute myocardial infarction and strongly predicts early mortality. Circulation, 1997; 96: 3338-3345.

12. Ellekilde G, von Eyben FE, Holm J, Hemmingsen L. Above normal urinary excretion of albumin and retinol-binding protein in patients with acute myocardial infarction. Clin Chem, 1993; 39: 50-51.

13. Berton R, Cordiano R, Palmieri F, Cucchini R, De Toni R, Palatini P. Microalbuminuria during acute myocardial infarction. A strong predictor for 1-year morbidity G. Eur Heart J, 2001; 22: 1466-1475.

14. Koulouris S, Lekatsas I, Karabinos I et al. Microalbuminuria: A strong predictor of 3-year adverse prognosis in non-diabetic patients with acute myocardial infarction. Am Heart J, 2005; 149: 840-845.

15. Jensen JS, Clausen P, Borch-Johnsen K, Jensen G, Feldt-Rasmussen B. Detecting microalbuminuria by urinary albumin/keratinize concentration ratio. Nephrol Dial Transplant, 1997; 12S2: 6-9.

16. Nazer B, Ray KK, Murphy SA, Gibson M, Cannon CP. Urinary albumin concentration and long-term cardiovascular risk in acute coronary syndrome patients: A PROVE IT-TIMI 22 sub-study. J Thromb Thrombolysis, 2013; 36: 233-239.

17. Heart Outcomes Prevention Evaluation Study Investigators. Effects of ramipril on cardiovascular and microvascular outcomes in people with diabetes mellitus: Results of the HOPE study and MICRO HOPE sub-study. Lancet, 2000; 355: 253-259.
18. Estacio RO, Dale RA, Schrier R, Krantz MJ. Relation of reduction in urinary albumin excretion to ten-year cardiovascular mortality in patients with type 2 diabetes and systemic hypertension. Am J Cardiol, 2012; 109: 1743-1748.

19. Dogra G, Rich L, Stanton K, Watts GF. Endothelium-dependent and independent vasodilation studied at normoglycaemia in type 1 diabetes mellitus with and without microalbuminuria. Diabetologia, 2001; 44: 593-601.

20. Stehouwer CD, Nauta JJ, Zeldenrust GC, Hackeng WH, Donker AJ. Urinary albumin excretion, cardiovascular disease and endothelial dysfunction in non-insulin-dependent diabetes mellitus. Lancet, 1992; 340: 319-323.

21. Deckert T, Feldt-Rasmussen B, Borch-Johnsen K, Jensen T, Kofoed-Enevoldsen A. Albumunuria reflects under-spread vascular damage: the steno hypothesis. Diabetologia, 1989; 32:219-226. Rutter MK, McComg JM, Foster J, et al. Increased left ventricular mass index and nocturnal systolic blood pressure in patients with type 2 diabetes mellitus and microalbuminuria. Diabet Med 2000; 17(4): 321-325.

22. Ross R. The pathogenesis of atherosclerosis: An update. N Engl J Med, 1986; 314: 488-500.

23. Collier A, Leach JP, McLellan A, Jardine A, Morton JJ, Small M. Plasma endothelin-like immuno-reactivity levels in type 1 diabetic patients with microalbuminuria. Diabetes Care, 1992; 15: 1083-1040.

24. Neri S, Bruno CM, Leotta C, D'Amico RA, Pennisi G, Ierna D. Early endothelial alterations in type 2 diabetes. Int J Clin Lab Res, 1998; 28: 100-103.

25. Jager A, van Hinsbergh VW, Kostense PJ et al. Increased levels of soluble vascular adhesion molecule 1 are associated with risk of cardiovascular morbidity on type 2 diabetes: The Hoorn Study. Diabetes, 2000; 49: 485-491.

26. Koga M, Otsuki M, Kubo M, Hashimoto J, Kasayama S. Relationship between circulating vascular cell adhesion molecule-1 and microvascular complications in type 2 diabetes mellitus. Diabet Med, 1998; 15: 661-667.

27. Fasching P, Veitl M, Rohac M et al. Elevated concentrations of circulating adhesion molecules and their association with microvascular complications in insulin-dependent diabetes mellitus. J Clin Endocrinol Metab, 1996; 81: 4313-4317.

28. Mullen MJ, Clarkson P, Donald AE et al. Effect of enalapril on endothelial function in young insulin-dependent diabetic patients: A randomized, double-blind study. J Am Coll Cardiol, 1998; 31: 1330-1335.

29. Arcaro G, Zenere BM, Saggiani F et al. ACE inhibitors have recently been shown to improve endothelial function in type 1 diabetic patients with normal arterial pressure and microalbuminuria. Diabetes Care, 1999; 22: 1536-1542.

30. Parving HH, Lehnert CE, Brochner-Mortensen J, Gomis R, Andersen S, Arer P. The effect of ibersartan on the development of diabetic nephropathy in patients with type 2 diabetes. $\mathrm{N} \mathrm{Engl}$ Med, 2001; 345: 870-878. 